\section{BRAZIULIAN JOURNAL \\ OF MEDICAL AND BIOLOCICAL RESFARCH}

www.bjournal.com.br
ISSN 0100-879X

Volume 43 (7) 600-697 July 2010

BIOMEDICAL SCIENCES

AND

CLINICAL INVESTIGATION

Braz J Med Biol Res, July 2010, Volume 43(7) 611-618

doi: 10.1590/S0100-879X2010007500049

Helicobacter pylori adhesion to gastric epithelial cells is mediated by glycan receptors

A. Magalhães and C.A. Reis

The Brazilian Journal of Medical and Biological Research is partially financed by
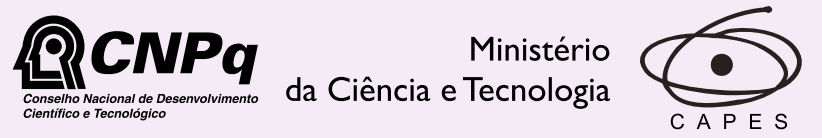

Ministério da Educação

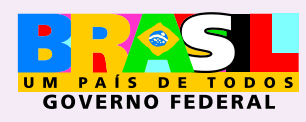

DTAPESP

Institutional Sponsors
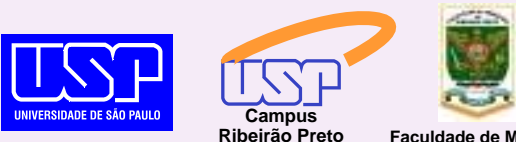

Ф SHIMADZU

GE Healthcare
Hotsite of proteomics metabolomics developped by: 


\title{
Helicobacter pylori adhesion to gastric epithelial cells is mediated by glycan receptors
}

\author{
A. Magalhães ${ }^{1,2}$ and C.A. Reis 1,2 \\ ${ }^{1}$ Instituto de Patologia e Imunologia Molecular da Universidade do Porto, Porto, Portugal \\ ${ }^{2}$ Faculdade de Medicina, Universidade do Porto, Porto, Portugal
}

\begin{abstract}
Helicobacter pylori adhesion to gastric epithelial cells constitutes a key step in the establishment of a successful infection of the gastric mucosa. The high representation of outer membrane proteins in the bacterial genome suggests the relevance of those proteins in the establishment of profitable interactions with the host gastric cells. Gastric epithelial cells are protected by a mucous layer gel, mainly consisting of the MUC5AC and MUC6 mucins. In addition to this protective role, mucins harbor glycan-rich domains that constitute preferential binding sites of many pathogens. In this article, we review the main players in the process of $H$. pylori adhesion to gastric epithelial cells, which contribute decisively to the high prevalence and chronicity of $H$. pylori infection. The BabA adhesin recognizes both $\mathrm{H}$-type 1 and Lewis b blood-group antigens expressed on normal gastric mucosa of secretor individuals, contributing to the initial steps of infection. Upon colonization, persistent infection induces an inflammatory response with concomitant expression of sialylated antigens. The SabA adhesin mediates $H$. pylori binding to inflamed gastric mucosa by recognizing sialyl-Lewis a and sialyl-Lewis $x$ antigens. The expression of the BabA and SabA adhesins is tightly regulated, permitting the bacteria to rapidly adapt to the changes of glycosylation of the host gastric mucosa that occur during infection, as well as to escape from the inflammatory response. The growing knowledge of the interactions between the bacterial adhesins and the host receptors will contribute to the design of alternative strategies for eradication of the infection.
\end{abstract}

Key words: Helicobacter pylori; Bacterial adhesins; Lewis antigens; Glycan receptors; Chronic gastritis; Gastric carcinogenesis

\section{Helicobacter pylori and gastric carcinogenesis}

Helicobacter pylori is a Gram-negative spiral-shaped microaerophilic bacterium specialized in the colonization of the human stomach, that infects more than a half of the world's population (1). Although most infected individuals show no clinical symptoms, $H$. pylori can cause gastric ulcers and persistent infection may cause chronic atrophic gastritis with the development of intestinal metaplasia (IM), dysplasia and gastric carcinoma (2). Gastric adenocarcinoma is the second cause of cancer death worldwide. In 1994, based on epidemiologic evidence, the International Agency for Research on Cancer classified $H$. pylori as a class I carcinogenic agent. The crucial role of $H$. pylori in the carcinogenic pathway was further confirmed using various animal models, which demonstrated that $H$. pylori infection induced gastritis, IM and gastric carcinoma $(3,4)$. The development of disease upon infection depends on bacterial virulence factors, host susceptibility features and other environmental factors such as smoking and diet. Among the bacterial virulence factors, the CagA protein encoded within the cytotoxin-associated gene pathogenicity island (cagPAI) and the vacuolating cytotoxin VacA have been demonstrated to be important features in determining the clinical outcome of $H$. pylori infection (5). In addition, genetic polymorphisms in genes codifying for host inflammatory cytokines, including IL-1B, TNF-A, IL-10, and IL-8, as well as in genes participating in the innate immune response such as TLR4, confer an increased risk of gastric cancer and its precursor lesions development in the presence of $H$. pylori (6).

\section{Mucins and their role in the host-pathogen interplay}

Mucins are heavily glycosylated high molecular weight

Correspondence: C.A. Reis, Instituto de Patologia e Imunologia Molecular, Universidade do Porto (IPATIMUP),

Rua Dr. Roberto Frias, s/n, 4200-465 Porto, Portugal. Fax: +351-2-2557-0799. E-mail: celsor@ipatimup.pt

Partially presented at the XXXVIII Annual Meeting of the Sociedade Brasileira de Bioquímica e Biologia Molecular, Águas de Lindóia, SP, Brazil, May 16-19, 2009.

Received March 14, 2010. Accepted May 24, 2010. Available online June 7, 2010. Published July 9, 2010. 
glycoproteins synthesized by several secretory epithelial cells. Mucins can be produced either as membrane-bound or secreted products and constitute the major component of the mucous viscous gels that lubricate and act as a physical barrier, providing protection for epithelial cells that line the respiratory and gastrointestinal tracts and form the ductal surfaces of organs such as the breast, pancreas and kidney (7).

The human mucin (MUC) family includes 21 members (MUC1 to MUC21) with a common structural feature: a tandem repeat domain comprising sequences of amino acids repeated in tandem, which are rich in proline, threonine and serine residues, constituting the PTS (Pro/Thr/Ser) domains. These domains are extensively glycosylated through GalNAc O-linkages at the serine and threonine residues (7).

In a healthy gastric mucosa, the mucins produced include MUC1, MUC5AC and MUC6. The membraneassociated MUC1 is expressed in foveolar cells and, to a lesser extent, in mucous glands. The secreted MUC5AC mucin is restricted to the foveolar epithelium and is a major constituent of the surface mucous gel layer, whereas the expression of the secreted MUC6 is limited to the glands (8-10). This mucin distribution determines the gastric glycosylation pattern since expression of MUC5AC is accompanied by similar distribution of fucosyltransferases leading to co-expression of type 1 Lewis a $\left(\mathrm{Le}^{\mathrm{a}}\right)$ and Lewis b $\left(\mathrm{Le}^{\mathrm{b}}\right)$ blood group antigens, while MUC6 expression is associated with the type 2 Lewis $x\left(L^{x}\right)$ and Lewis $y\left(L^{y}\right)$ antigens (Figure 1) (11).

$H$. pylori is mainly found within the gastric mucous layer and rarely colonizes deeper portions of the gastric mucosa. This distribution has been explained based on the production of mucins carrying carbohydrate chains with terminal $\alpha 1,4-G l c N A c$ residues attached to core2-branched O-glycans by the gland's mucous cells $(12,13)$. In vitro experiments show that $\alpha 1,4-$ GlcNAc-capped O-glycans function as a natural antibiotic by inhibiting the biosynthesis of a major cell wall component and thus hampering $H$. pylori growth (13). Recently, it has been demonstrated that the membrane-associated MUC1 can limit $H$. pylori binding to gastric epithelial cells both by steric inhibition of binding to other cell surface ligands and by acting as a releasable decoy (14). These observations are in agreement with previous studies showing that mice deficient in Muc1 were more susceptible to $H$. pylori infection (15).

Chronic gastritis occasionally evolves to IM, characterized by the aberrant expression of MUC2 and the sialyl-Tn antigen, which are markers normally expressed in intestinal mucosa $(12,16)$. Two distinct profiles of mucin expression have been described in IM, one corresponding to the complete type characterized by decreased expression of MUC1, MUC5AC and MUC6 and de novo expression of MUC2, and the other corresponding to the incomplete type characterized by the co-expression of the typical gastric mucins MUC1, MUC5AC and MUC6 with the intestinal
MUC2 (16). Complete IM is not colonized by H. pylori but a few cases of incomplete IM with $H$. pylori colonization have been described, suggesting that infection is dependent on the gastric microenvironment, which is largely determined by the mucin and carbohydrate composition of the gastric mucin layer $(10,17)$.

\section{Helicobacter pylori adhesion to human gastric mucosa}

H. pylori colonizes the gastric mucosa by adhering to the mucous epithelial cells and the mucous layer lining the gastric epithelium. Adhesion to the gastric cells is a crucial step in the establishment of a successful infection because it provides protection from clearance mechanisms such as liquid flow, peristaltic movements or shedding of the mucous layer. Approximately $4 \%$ of the $H$. pylori coding potential encodes a diverse repertoire of outer membrane proteins including the Helicobacter outer membrane porins (Hop) and Hop-related protein (Hor) subfamilies. The currently identified adhesins are phylogenetically clustered in the Hop subfamily and display a substantial degree of homology to each other $(18,19)$.

\section{Blood group antigen-mediated Helicobacter pylori adhesion}

In the early 90's, in vitro adhesion assays identified the fucosylated blood group antigens $\mathrm{H}$-type 1 and Le ${ }^{b}$ as mediators of $H$. pylori adhesion to human gastric epithelial cells (20). Later the Le ${ }^{b}$-binding adhesin, named blood group antigen-binding adhesin (BabA), was identified and purified by receptor activity-directed affinity tagging (Figure 2). Two corresponding genes encoding BabA have been cloned: babA1 and babA2, but only the babA2 gene was shown to be functionally active (21). H. pylori strains expressing the BabA adhesin were shown to bind to the human gastric MUC5AC from healthy individuals in a Lewis b-dependent manner $(22,23)$.

The bacterial Lewis b-binding phenotype is epidemiologically associated with the presence of the cagPAI $(21,24)$. Several studies have established the clinical relevance of the babA2 gene, suggesting it as a marker to identify patients at higher risk for specific $H$. pylori-related diseases $(24,25)$. Considering the clinical relevance of BabA, a vaccine strategy based on this adhesin might be used to target virulent strains of $H$. pylori $(21,26)$.

$H$. pylori strains are able to adapt their outer membrane expression profile according to alterations in host environment, including changes in mucosal glycosylation patterns, by switching on and off gene expression. The presence of highly homologous genes allows allelic replacement between genomic areas with different transcriptional activity. It has been demonstrated in vitro that if the babA2 gene is disrupted the bacteria can regain the Le $\mathrm{e}^{\mathrm{b}}$-binding phenotype 


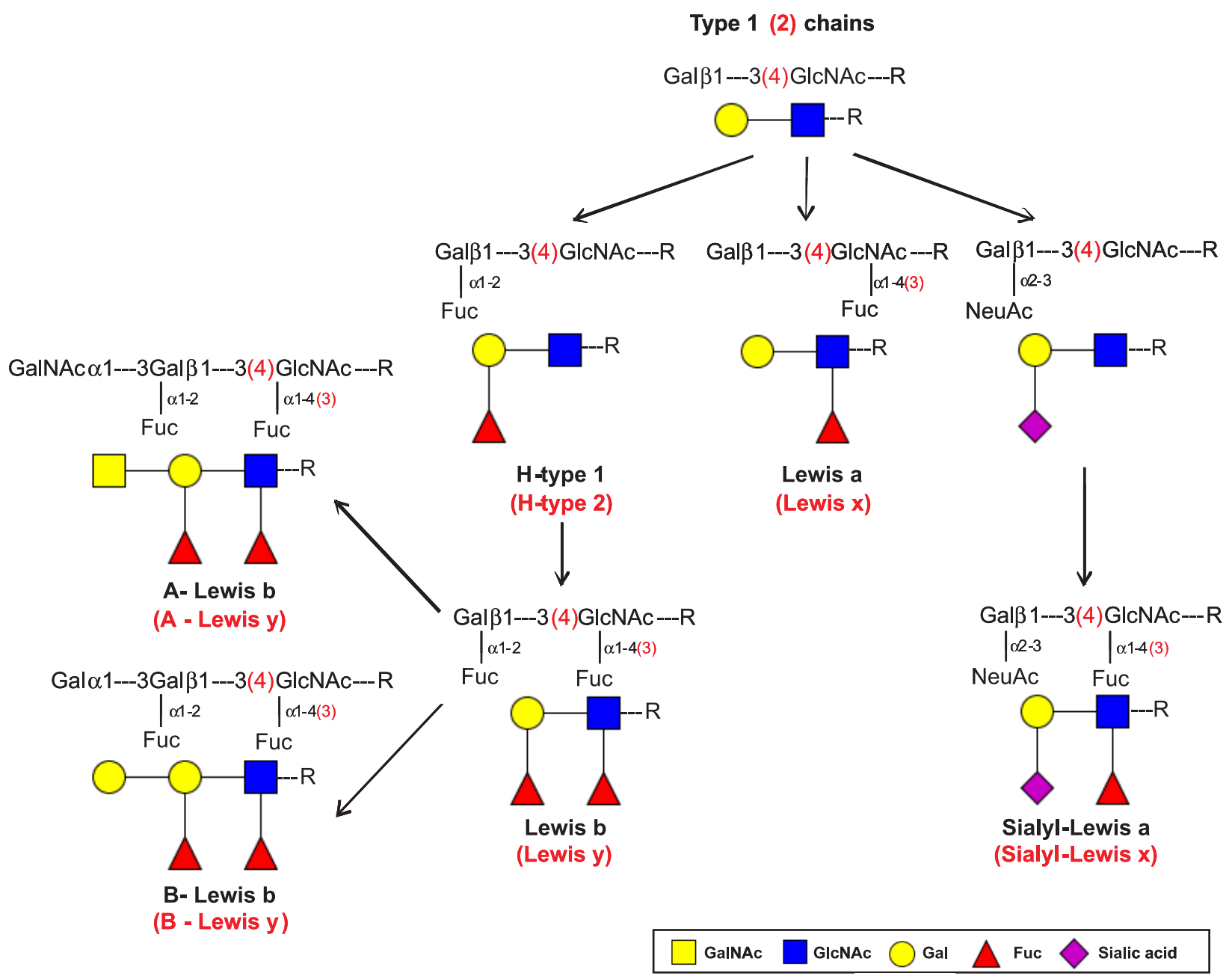

Figure 1. Schematic representation of the terminal $A B H$ structures and Lewis epitopes present in O-glycans. Type 1 chains are characterized by the Galß1,3GlcNAc linkage (represented in black), while type 2 chains display a Galß1,4GlcNAc linkage (represented between parentheses and in red).

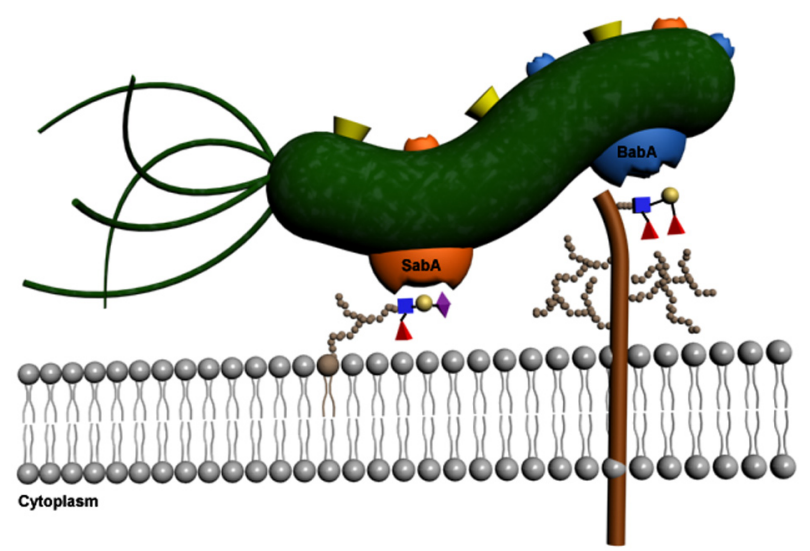

Figure 2. Glycan-mediated adhesion of Helicobacter pylori to gastric cells. The figure illustrates some of the characterized bacterialglycan interactions that contribute to a successful colonization of the gastric mucosa. H. pylori BabA mediates binding to either Lewis b or $\mathrm{H}$-type 1 structures (not represented in the figure) present in secreted or membrane-associated glycoproteins expressed on the gastric mucosa of healthy secretor individuals, while SabA recognizes the inflammation-induced sialylated antigens, sialyl-Lewis a and sialylLewis $\mathrm{x}$ expressed on glycoproteins and glycolipids. Although the host receptors have not yet been determined, several other bacterial adhesins (represented in yellow) may contribute to bacterial binding to gastric epithelial cells. 
by recombining the silent babA1 gene into the babB locus where it is then expressed, encoding a functionally active adhesin (27). Moreover, reisolated strains from Rhesus macaques infected with a BabA-positive strain lost their Lewis b-binding capacity by switching off babA expression either by slipped-strand mispairing (SSM) or by recombination of the babB gene into the babA locus (28). Recently, these observations have been extended to different animal hosts, including mice and gerbils, and six amino acid changes in the BabA sequence have been identified as sufficient to abolish the Le ${ }^{\mathrm{b}}$-binding phenotype (29). BabA metastability and heterogeneity in $\mathrm{Le}^{\mathrm{b}}$ antigen binding contributes to bacterial persistence, allowing periodic activation and deactivation of virulence adequate to the host response to infection (27,30). The plasticity of BabA adhesin has also been illustrated by the finding that some $H$. pylori strains are generalists, which means that they are able to tolerate the GalNAc (blood group-A) or Gal (blood group-B) terminal structures and bind $A-L e^{b}$ and $B-L e^{b}$ in addition to $L e^{b}$, while other strains, so-called specialists, exclusively bind to naked $\mathrm{Le}^{\mathrm{b}}$ and a few strains exclusively bind to A-Le ${ }^{\mathrm{b}}$ (Figure 1) (31). More recently, H. pylori strains, which express BabA adhesin but are unable to bind any Le ${ }^{b}$ structure, have been described (32).

The fucosylated $\mathrm{H}$-type 1 and $\mathrm{Le}^{\mathrm{b}}$ antigens are naturally expressed on the gastric mucosa of secretor and Lewispositive individuals. The secretor status depends on an active FUT2 enzyme, an $\alpha(1,2)$ fucosyltransferase that catalyzes the addition of terminal $\alpha(1,2)$ fucose residues (33). Inactivating mutations in the secretor gene affect $20 \%$ of the human population and have been associated with reduced susceptibility to infections by Norwalk virus and $H$. pylori (34-37). We have used an animal model of non-secretors, the Fut2-null mice, to characterize the glycosylation profile and evaluate the effect of the observed glycan expression modifications in $H$. pylori adhesion. As expected, Fut2-null mice showed marked alteration in gastric mucosa glycosylation, characterized by diminished expression of $\alpha(1,2)$ fucosylated structures. This altered glycosylation profile resulted in the absence of Fuca(1,2)-dependent binding of calicivirus virus-like particles. Regarding $H$. pylori adhesion, we observed that strains expressing a functional $\mathrm{BabA}$ adhesin showed decreased adhesion to the gastric mucosa of Fut2-null mice whereas the binding pattern of strains that only express the sialic acid-binding adhesin SabA was not altered, demonstrating that this impaired adhesion could be strictly attributed to reduced expression of BabA ligands in the gastric mucosa of Fut2-null mice (38).

\section{Helicobacter pylori adhesion during persistent infection}

Persistent $H$. pylori colonization of the gastric mucosa results in inflammation with concomitant expression of sialylated glycans such as sialyl-Le ${ }^{a}$ and sialyl-Le ${ }^{\mathrm{x}}$ (Figures 1 and 2) $(39,40)$. Parallel to what was described for humans, in the Rhesus monkey model, $H$. pylori infection resulted in an increase of sialylated mucosal antigens and a concomitant decrease in fucosylated antigens (41). Similar to BabA, the sialic acid-binding adhesin, SabA, has been identified by the retagging technique based on its affinity for sialyl-Le ${ }^{\mathrm{x}}$ (39). The minimal structure required for SabA adhesin binding was shown to be NeuAca2-3Gal $(42,43)$. Accordingly, it has been demonstrated that SabA interaction with the host gastric sialyl-Le ${ }^{x}$ antigen enhances $H$. pylori colonization in patients with weak or no Leb expression (44).

Recently, we have demonstrated that $H$. pylori infection induces several alterations in the glycosylation-related gene expression profile of a human gastric cell line. Interestingly, the observed gene expression modifications were highly related to the degree of pathogenicity of the infecting $H$. pylori strain (45). Among the genes that were up-regulated by $H$. pylori, a specific glycosyltransferase, $\beta 3$ GIcNAcT5, was identified and this enzyme was reported to be involved in the biosynthesis pathway of carbohydrate chains such as sialyl-Le ${ }^{x}$ on glycolipids. The induction of $\beta 3$ GIcNAcT5 expression was specific of the highly pathogenic cagPAl-positive strains. In vitro experiments demonstrated that overexpression of the $\beta 3$ GICNAcT5 enzyme led to an up-regulation of sialyl-Le ${ }^{\mathrm{x}}$ expression, concomitant with increased $H$. pylori SabA-mediated adhesion to gastric cells (45).

As previously described for the babA gene, sabA gene expression can be modulated by phase variation through SSM. The length of a dinucleotide cytosine-thymine repeat tract near the 5' end of the open reading frame determines if translation results in a truncated non-functional protein or in a full-length functional adhesin $(39,46)$. In addition to SSM, SabA protein production is also controlled at the transcriptional level by the acid-responsive signal (ArsRS) two-component signal transduction regulatory system (46). This capacity of rapidly switching on and off BabA and SabA expression allows a continuous adaptation of the bacterial binding properties to the glycan profile modifications that occur during the inflammation process. This adaptation is essential for the maintenance of a chronic infection.

\section{Other players that participate in the Helicobacter pylori adhesion process}

Although BabA and SabA are the most prominent adhesins studied in detail so far, it is important to note that not every $H$. pylori strain expresses functional BabA or SabA adhesins, suggesting that other bacterial proteins are involved in $H$. pylori adhesion to gastric cells. It has been demonstrated that the adherence-associated lipoprotein A and B (AlpA and AlpB) and HopZ participate in H. pylori binding, but its corresponding host receptors remain to be determined $(19,47,48)$. Additionally, two sulfo-binding $H$. pylori proteins have been described, the neutrophil- 
activating protein (NAP), which binds specifically to sulfated oligosaccharide structures such as sulfo-Le ${ }^{a}$, sulfogalactose and sulfo- $\mathrm{N}$-acetyl-glucosamine on mucins, and $\mathrm{Hsp} 70$ that has been suggested to mediate sulfatide recognition under stress conditions $(49,50)$. Heparan sulfate glycosaminoglycans have also been described to have a role in $\mathrm{H}$. pylori adhesion to cell-line models $(51,52)$. In vitro studies have shown that $H$. pylori infection up-regulates expression of syndecan-4, which represents one of the major sources of heparan-sulfate on the cell surface $(53,54)$. These results were further validated in vivo by demonstrating that $H$. pyloriinfected individuals expressed syndecan-4 in the foveolar epithelium of the gastric mucosa and that this expression was dependent on the cagPAl status of the infecting strain (53). Although several studies have favored a role for heparan sulfate glycosaminoglycans in the process of bacterial adhesion to epithelial cells there is still no explanation of how the induction of syndecan-4 by highly pathogenic $H$. pylori strains can contribute to the higher aggressiveness of these strains.

\section{Helicobacter pylori mimics the host Lewis antigens}

Lipopolysaccharide (LPS) is a structural component of the outer cell wall of all Gram-negative bacteria. LPS is composed of a long-chain fatty acid anchor called lipid A, a core sugar chain, and a variable carbohydrate chain named $\mathrm{O}$ antigen. In contrast to several other pathogens, $H$. pylori LPS is of very low toxicity to the host. Interestingly, the $\mathrm{O}$ antigen of $H$. pylori shares structural homology with the Lewis blood group antigens expressed in human gastric mucosa, including antigens based on both type 1 chains, namely Le ${ }^{a}$ and $\mathrm{H}$-type 1 , and type 2 chains, like Le ${ }^{\mathrm{x}}$ and Ley (Figure 1) (55). The expression of these antigens undergoes phase variation, with different bacterial fucosyltransferases being switched on and off, contributing to a dynamic glycosylation even in the same host. It has been proposed that Le ${ }^{x}$ structures expressed by the $H$. pylori $\mathrm{O}$ antigen side-chain may promote adhesion to gastric epithelial cells, but the relevance of this interaction as well as the nature of the Le $\mathrm{x}^{\mathrm{x}}$-receptors in gastric mucosa remain unknown $(56,57)$. Beside the potential role in bacterial adhesion, this antigen mimicry may contribute to immune tolerance towards bacterial antigens (58). Furthermore, this mimicry process can induce the production of autoantibodies that recognize the host gastric epithelial cells, favoring the development of autoimmune-associated disease (58).

\section{Strategies to inhibit Helicobacter pylori binding to human gastric mucosa}

The increasing antibiotic resistance associated with $H$. pylori eradication by antimicrobial therapy is raising the need to search for alternative strategies such as those based on blocking bacterial adhesion to host receptors. A strategy of carbohydrate-dependent inhibition of $H$. pylori colonization using porcine milk has been tested with success in mice, suggesting that milk from certain pig breeds may have a therapeutic and or prophylactic effect on $H$. pylori infection (59). In addition, ongoing studies are addressing the potential of using synthetic carbohydrates to inhibit $H$. pylori adhesion to gastric epithelial cells.

A human domain antibody specific for BabA adhesin has been recently isolated and proved to efficiently inhibit $\mathrm{Le}^{\mathrm{b}}$ binding and to prevent adhesion of BabA-expressing $H$. pylori strains to human gastric mucosa (60). These experiments suggest its potential therapeutic application in combination with Le ${ }^{\mathrm{b}}$ glycoconjugates in the treatment of antibiotic-resistant $H$. pylori infection.

\section{Final remarks}

Although $H$. pylori levels of infection are decreasing, the number of infected individuals is still very high, with half of the world population estimated to be infected. Antibiotic-based eradication therapies should be carefully considered due to the observed increased antibiotic resistance. Knowing that infection and persistent colonization of human gastric mucosa by $H$. pylori is highly dependent on bacterial adhesion to gastric epithelial cells, an effort should be made in order to better understand which bacterial lectin-host glycan interactions are truly critical for adhesion. Mucin type-O glycans have been demonstrated to be crucial players in the interaction between the bacteria and host gastric epithelial cells. The BabA adhesin recognizes both $\mathrm{Le}^{\mathrm{b}}$ and $\mathrm{H}$-type 1 structures expressed by the gastric epithelial cells of healthy secretors, while SabA mediates adhesion to inflamed gastric mucosa by binding the sialylated sialyl-Le ${ }^{a}$ and sialyl-Le ${ }^{\mathrm{x}}$ antigens (Figure 2). However, some $H$. pylori strains express neither BabA nor SabA adhesins, which implies that other outer membrane proteins, already described or still unidentified, are participating in the adhesion process.

The clarification of why only a small percentage of $H$. pylori-infected individuals develop disease remains a major puzzling question regarding $H$. pylori infection. Besides the current knowledge of host genetic polymorphisms, bacterial virulence features and environmental factors that contribute to the clinical outcome of $H$. pylori infection, it is expected that the diversity of carbohydrate expression on gastric mucosa among individuals may confer distinct susceptibilities to $H$. pyloricolonization and infection. This is demonstrated by the reduced susceptibility of non-secretor individuals to become infected by BabA-expressing H. pylori strains.

The characterization of the glycan receptors essential for $H$. pyloriadhesion will allow the identification of individuals at higher risk to develop $H$. pylori infection-associated diseases, as well as the design of new infection eradication strategies based on inhibition of bacterial adhesion to gastric epithelial cells. 


\section{Acknowledgments}

We thank Professor Leonor David for a critical reading of the manuscript and suggestions. Research supported by Fundação para a Ciência e a Tecnologia (FCT, PIC/ IC/82716/2007 and PDTC/CTM/65330/2006) financiados no âmbito Programa Operacional Ciência e Inovação

\section{References}

1. Atherton JC. The pathogenesis of Helicobacter pyloriinduced gastro-duodenal diseases. Annu Rev Pathol 2006; 1: 63-96.

2. Correa P, Houghton J. Carcinogenesis of Helicobacter pylori. Gastroenterology 2007; 133: 659-672.

3. Fujioka T, Honda S, Tokieda M. Helicobacter pylori infection and gastric carcinoma in animal models. J Gastroenterol Hepatol 2000; 15 (Suppl): D55-D59.

4. Watanabe T, Tada M, Nagai H, Sasaki S, Nakao M. Helicobacter pylori infection induces gastric cancer in Mongolian gerbils. Gastroenterology 1998; 115: 642-648.

5. van Doorn LJ, Figueiredo C, Sanna R, Plaisier A, Schneeberger $\mathrm{P}$, de Boer $\mathrm{W}$, et al. Clinical relevance of the cagA, vacA, and iceA status of Helicobacter pylori. Gastroenterology 1998; 115: 58-66.

6. Amieva MR, El-Omar EM. Host-bacterial interactions in Helicobacter pylori infection. Gastroenterology 2008; 134: 306-323.

7. Kufe DW. Mucins in cancer: function, prognosis and therapy. Nat Rev Cancer 2009; 9: 874-885.

8. Reis CA, David L, Carvalho F, Mandel U, de Bolos C, Mirgorodskaya $\mathrm{E}$, et al. Immunohistochemical study of the expression of MUC6 mucin and co-expression of other secreted mucins (MUC5AC and MUC2) in human gastric carcinomas. $J$ Histochem Cytochem 2000; 48: 377-388.

9. Reis CA, David L, Seixas M, Burchell J, Sobrinho-Simoes M. Expression of fully and under-glycosylated forms of MUC1 mucin in gastric carcinoma. Int J Cancer 1998; 79: 402410.

10. Teixeira A, David L, Reis CA, Costa J, Sobrinho-Simoes M. Expression of mucins (MUC1, MUC2, MUC5AC, and MUC6) and type 1 Lewis antigens in cases with and without Helicobacter pylori colonization in metaplastic glands of the human stomach. J Pathol 2002; 197: 37-43.

11. De Bolos C, Garrido M, Real FX. MUC6 apomucin shows a distinct normal tissue distribution that correlates with Lewis antigen expression in the human stomach. Gastroenterology 1995; 109: 723-734.

12. Ferreira B, Marcos NT, David L, Nakayama J, Reis CA. Terminal alpha1,4-linked $\mathrm{N}$-acetylglucosamine in Helicobacter pylori-associated intestinal metaplasia of the human stomach and gastric carcinoma cell lines. J Histochem Cytochem 2006; 54: 585-591.

13. Kawakubo M, Ito $Y$, Okimura $Y$, Kobayashi M, Sakura K, Kasama $S$, et al. Natural antibiotic function of a human gastric mucin against Helicobacter pylori infection. Science 2004; 305: 1003-1006.

14. Linden SK, Sheng YH, Every AL, Miles KM, Skoog EC, Florin $\mathrm{TH}$, et al. MUC1 limits Helicobacter pylori infection both by
2010 do Quadro Comunitário de Apoio III e comparticipados pelo FEDER. A. Magalhães (SFRH/BD/36339/2007) acknowledges FCT for financial support. IPATIMUP is an Associate Laboratory of the Portuguese Ministry of Science, Technology and Higher Education and is partially supported by FCT, the Portuguese Foundation for Science and Technology. steric hindrance and by acting as a releasable decoy. PLOS Pathog 2009; 5: e1000617.

15. McGuckin MA, Every AL, Skene CD, Linden SK, Chionh YT, Swierczak A, et al. Muc1 mucin limits both Helicobacter pylori colonization of the murine gastric mucosa and associated gastritis. Gastroenterology 2007; 133: 1210-1218.

16. Reis CA, David L, Correa P, Carneiro F, De Bolos C, Garcia $\mathrm{E}$, et al. Intestinal metaplasia of human stomach displays distinct patterns of mucin (MUC1, MUC2, MUC5AC, and MUC6) expression. Cancer Res 1999; 59: 1003-1007.

17. Silva E, Teixeira A, David L, Carneiro F, Reis CA, SobrinhoSimoes J, et al. Mucins as key molecules for the classification of intestinal metaplasia of the stomach. Virchows Arch 2002; 440: 311-317.

18. Tomb JF, White O, Kerlavage AR, Clayton RA, Sutton GG, Fleischmann RD, et al. The complete genome sequence of the gastric pathogen Helicobacter pylori. Nature 1997; 388: 539-547.

19. Odenbreit S. Adherence properties of Helicobacter pylori: impact on pathogenesis and adaptation to the host. Int $J$ Med Microbiol 2005; 295: 317-324.

20. Boren T, Falk P, Roth KA, Larson G, Normark S. Attachment of Helicobacter pylori to human gastric epithelium mediated by blood group antigens. Science 1993; 262: 1892-1895.

21. Ilver D, Arnqvist A, Ogren J, Frick IM, Kersulyte D, Incecik ET, et al. Helicobacter pylori adhesin binding fucosylated histo-blood group antigens revealed by retagging. Science 1998; 279: 373-377.

22. Linden $\mathrm{S}$, Nordman $\mathrm{H}$, Hedenbro J, Hurtig $\mathrm{M}$, Boren $\mathrm{T}$, Carlstedt I. Strain- and blood group-dependent binding of Helicobacter pylori to human gastric MUC5AC glycoforms. Gastroenterology 2002; 123: 1923-1930.

23. Van de Bovenkamp JH, Mahdavi J, Korteland-Van Male AM, Buller HA, Einerhand AW, Boren T, et al. The MUC5AC glycoprotein is the primary receptor for Helicobacter pylori in the human stomach. Helicobacter 2003; 8: 521-532.

24. Gerhard M, Lehn N, Neumayer N, Boren T, Rad R, Schepp $\mathrm{W}$, et al. Clinical relevance of the Helicobacter pylori gene for blood-group antigen-binding adhesin. Proc Natl Acad Sci U S A 1999; 96: 12778-12783.

25. Yu J, Leung WK, Go MY, Chan MC, To KF, Ng EK, et al. Relationship between Helicobacter pylori babA2 status with gastric epithelial cell turnover and premalignant gastric lesions. Gut 2002; 51: 480-484.

26. Bai Y, Zhang YL, Chen Y, Jin JF, Zhang ZS, Zhou DY. Cloning and expression and immunogenicity of Helicobacter pylori BabA2 gene. World J Gastroenterol 2004; 10: 2560-2562.

27. Backstrom A, Lundberg C, Kersulyte D, Berg DE, Boren T, Arnqvist A. Metastability of Helicobacter pylori bab adhesin 
genes and dynamics in Lewis $b$ antigen binding. Proc Natl Acad Sci U S A 2004; 101: 16923-16928.

28. Solnick JV, Hansen LM, Salama NR, Boonjakuakul JK, Syvanen M. Modification of Helicobacter pylori outer membrane protein expression during experimental infection of Rhesus macaques. Proc Natl Acad Sci U S A 2004; 101: 2106-2111.

29. Styer CM, Hansen LM, Cooke CL, Gundersen AM, Choi SS, Berg DE, et al. Expression of the BabA adhesin during experimental infection with Helicobacter pylori. Infect Immun 2010; 78: 1593-1600.

30. Colbeck JC, Hansen LM, Fong JM, Solnick JV. Genotypic profile of the outer membrane proteins BabA and BabB in clinical isolates of Helicobacter pylori. Infect Immun 2006; 74: 4375-4378.

31. Aspholm-Hurtig M, Dailide G, Lahmann M, Kalia A, Ilver D, Roche N, et al. Functional adaptation of BabA, the $H$. pylori ABO blood group antigen binding adhesin. Science 2004; 305: 519-522.

32. Odenbreit S, Swoboda K, Barwig I, Ruhl S, Boren T, Koletzko $S$, et al. Outer membrane protein expression profile in Helicobacter pylori clinical isolates. Infect Immun 2009; 77: 3782-3790.

33. Mollicone R, Bara J, Le Pendu J, Oriol R. Immunohistologic pattern of type 1 (Lea, Leb) and type 2 (X, Y, H) blood group-related antigens in the human pyloric and duodenal mucosae. Lab Invest 1985; 53: 219-227.

34. Azevedo M, Eriksson S, Mendes N, Serpa J, Figueiredo C, Resende LP, et al. Infection by Helicobacter pylori expressing the BabA adhesin is influenced by the secretor phenotype. J Pathol 2008; 215: 308-316.

35. Ikehara Y, Nishihara S, Yasutomi H, Kitamura T, Matsuo K, Shimizu N, et al. Polymorphisms of two fucosyltransferase genes (Lewis and Secretor genes) involving type I Lewis antigens are associated with the presence of anti-Helicobacter pylori IgG antibody. Cancer Epidemiol Biomarkers Prev 2001; 10: 971-977.

36. Lindesmith L, Moe C, Marionneau S, Ruvoen N, Jiang X, Lindblad L, et al. Human susceptibility and resistance to Norwalk virus infection. Nat Med 2003; 9: 548-553.

37. Marionneau S, Cailleau-Thomas A, Rocher J, Le MoullacVaidye $\mathrm{B}$, Ruvoen $\mathrm{N}$, Clement $\mathrm{M}$, et al. $\mathrm{ABH}$ and Lewis histo-blood group antigens, a model for the meaning of oligosaccharide diversity in the face of a changing world. Biochimie 2001; 83: 565-573.

38. Magalhaes A, Gomes J, Ismail MN, Haslam SM, Mendes N, Osorio $\mathrm{H}$, et al. Fut2-null mice display an altered glycosylation profile and impaired BabA-mediated Helicobacter pylori adhesion to gastric mucosa. Glycobiology 2009; 19: 15251536.

39. Mahdavi J, Sonden B, Hurtig M, Olfat FO, Forsberg L, Roche $\mathrm{N}$, et al. Helicobacter pylori SabA adhesin in persistent infection and chronic inflammation. Science 2002; 297: 573578.

40. Ota H, Nakayama J, Momose M, Hayama M, Akamatsu T, Katsuyama T, et al. Helicobacter pylori infection produces reversible glycosylation changes to gastric mucins. Virchows Arch 1998; 433: 419-426.

41. Linden S, Mahdavi J, Semino-Mora C, Olsen C, Carlstedt I, Boren $\mathrm{T}$, et al. Role of ABO secretor status in mucosal innate immunity and H. pylori infection. PLoS Pathog 2008; 4: e2.

42. Walz A, Odenbreit S, Mahdavi J, Boren T, Ruhl S. Identifi- cation and characterization of binding properties of Helicobacter pylori by glycoconjugate arrays. Glycobiology 2005; 15: 700-708.

43. Aspholm M, Olfat FO, Norden J, Sonden B, Lundberg C, Sjostrom R, et al. SabA is the H. pylori hemagglutinin and is polymorphic in binding to sialylated glycans. PLoS Pathog 2006; 2: e110.

44. Sheu BS, Odenbreit S, Hung KH, Liu CP, Sheu SM, Yang $\mathrm{HB}$, et al. Interaction between host gastric Sialyl-Lewis $X$ and $H$. pylori SabA enhances $H$. pylori density in patients lacking gastric Lewis B antigen. Am J Gastroenterol 2006; 101: $36-44$

45. Marcos NT, Magalhaes A, Ferreira B, Oliveira MJ, Carvalho AS, Mendes N, et al. Helicobacter pylori induces beta3GnT5 in human gastric cell lines, modulating expression of the SabA ligand sialyl-Lewis x. J Clin Invest 2008; 118: 23252336.

46. Goodwin AC, Weinberger DM, Ford CB, Nelson JC, Snider JD, Hall JD, et al. Expression of the Helicobacter pylori adhesin SabA is controlled via phase variation and the ArsRS signal transduction system. Microbiology 2008; 154: 22312240.

47. Odenbreit S, Till M, Hofreuter D, Faller G, Haas R. Genetic and functional characterization of the alpAB gene locus essential for the adhesion of Helicobacter pylori to human gastric tissue. Mol Microbiol 1999; 31: 1537-1548.

48. Peck B, Ortkamp M, Diehl KD, Hundt E, Knapp B. Conservation, localization and expression of HopZ, a protein involved in adhesion of Helicobacter pylori. Nucleic Acids Res 1999; 27: 3325-3333.

49. Huesca M, Borgia S, Hoffman P, Lingwood CA. Acidic pH changes receptor binding specificity of Helicobacter pylori: a binary adhesion model in which surface heat shock (stress) proteins mediate sulfatide recognition in gastric colonization. Infect Immun 1996; 64: 2643-2648.

50. Namavar F, Sparrius M, Veerman EC, Appelmelk BJ, Vandenbroucke-Grauls CM. Neutrophil-activating protein mediates adhesion of Helicobacter pylori to sulfated carbohydrates on high-molecular-weight salivary mucin. Infect Immun 1998; 66: 444-447.

51. Lopez-Bolanos CC, Guzman-Murillo MA, Ruiz-Bustos E, Ascencio $\mathrm{F}$. The role of heparan sulfate on adhesion of 47 and $51 \mathrm{kDa}$ outer membrane proteins of Helicobacter pylori to gastric cancer cells. Can J Microbiol 2009; 55: 450-456.

52. Utt M, Wadstrom $T$. Identification of heparan sulphate binding surface proteins of Helicobacter pylori: inhibition of heparan sulphate binding with sulphated carbohydrate polymers. J Med Microbiol 1997; 46: 541-546.

53. Magalhaes A, Marcos NT, Carvalho AS, David L, Figueiredo C, Bastos J, et al. Helicobacter pylori cag pathogenicity island-positive strains induce syndecan-4 expression in gastric epithelial cells. FEMS Immunol Med Microbiol 2009; 56 : 223-232.

54. Smith MF Jr, Novotny J, Carl VS, Comeau LD. Helicobacter pylori and Toll-like receptor agonists induce syndecan-4 expression in an NF-kappaB-dependent manner. Glycobiology 2006; 16: 221-229.

55. Monteiro MA, Chan KH, Rasko DA, Taylor DE, Zheng PY, Appelmelk BJ, et al. Simultaneous expression of type 1 and type 2 Lewis blood group antigens by Helicobacter pylori lipopolysaccharides. Molecular mimicry between $H$. pylori lipopolysaccharides and human gastric epithelial cell surface 
glycoforms. J Biol Chem 1998; 273: 11533-11543.

56. Edwards NJ, Monteiro MA, Faller G, Walsh EJ, Moran AP, Roberts IS, et al. Lewis $X$ structures in the $O$ antigen sidechain promote adhesion of Helicobacter pylori to the gastric epithelium. Mol Microbiol 2000; 35: 1530-1539.

57. Mahdavi J, Boren T, Vandenbroucke-Grauls C, Appelmelk BJ. Limited role of lipopolysaccharide Lewis antigens in adherence of Helicobacter pylori to the human gastric epithelium. Infect Immun 2003; 71: 2876-2880.

58. Moran AP. Relevance of fucosylation and Lewis antigen expression in the bacterial gastroduodenal pathogen Heli- cobacter pylori. Carbohydr Res 2008; 343: 1952-1965.

59. Gustafsson A, Hultberg A, Sjostrom R, Kacskovics I, Breimer $\mathrm{ME}$, Boren $\mathrm{T}$, et al. Carbohydrate-dependent inhibition of Helicobacter pylori colonization using porcine milk. Glycobiology 2006; 16: 1-10.

60. Younson J, O'Mahony R, Liu H, Basset C, Grant S, Campion $\mathrm{C}$, et al. A human domain antibody and Lewis b glycoconjugate that inhibit binding of Helicobacter pylori to Lewis $b$ receptor and adhesion to human gastric epithelium. J Infect Dis 2009; 200: 1574-1582. 